\title{
Pneumothorax in a Patient with Unilateral Pulmonary Artery Agenesis
}

\author{
Moriyasu Anai ${ }^{1}$, Shinya Sakata ${ }^{1}$, Hiroto Kishi ${ }^{2}$ and Koichi Yatsunami ${ }^{3}$ \\ Key words: bullous lung disease, pneumothorax, unilateral pulmonary artery agenesis
}

(Intern Med 57: 145-147, 2018)

(DOI: 10.2169/internalmedicine.9093-17)

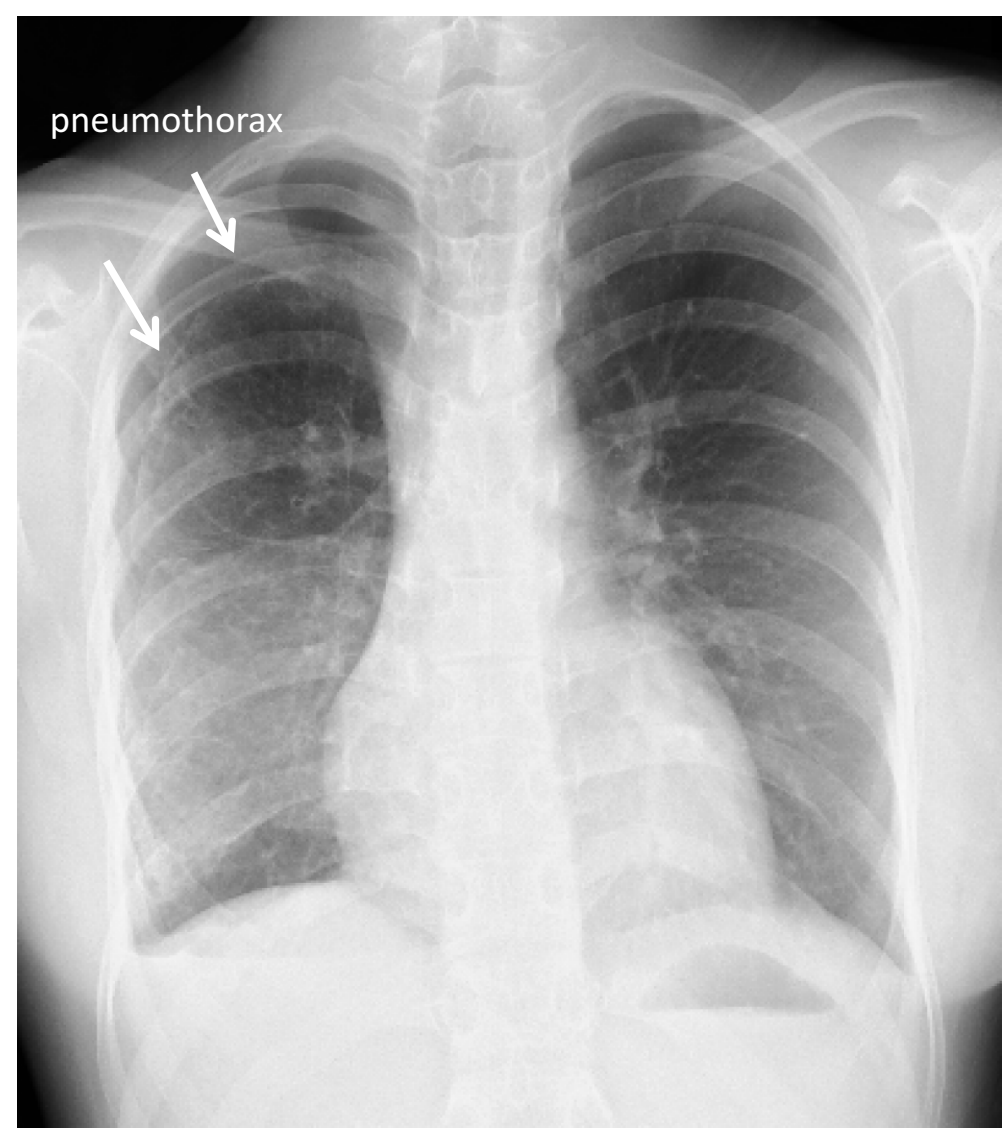

Picture 1.

A 17-year-old Japanese woman presented with right chest pain and exertional dyspnea. The patient had a history of isolated unilateral absence of the right pulmonary artery (UAPA) and pulmonary hypertension from early childhood. Chest radiography revealed right-sided pneumothorax and a small lung volume with mediastinal and tracheal shift to the right as well as right diaphragm elevation (Picture 1). Computed tomography revealed pneumothorax and multiple thinwalled bullae only in the right lung, and absence of the right main pulmonary artery (Picture 2). The pneumothorax improved without any invasive procedures, such as needle aspiration or chest tube drainage (Picture 3). In comparison to

${ }^{1}$ Department of Respiratory Medicine, Kumamoto University Hospital, Japan, ${ }^{2}$ Department of Respiratory Medicine, Kumamoto City Hospital, Japan and ${ }^{3}$ Department of Pediatric Cardiology, Kumamoto City Hospital, Japan

Received: February 24, 2017; Accepted: May 8, 2017; Advance Publication by J-STAGE: October 16, 2017

Correspondence to Dr. Shinya Sakata, sakata-1027@hotmail.co.jp 


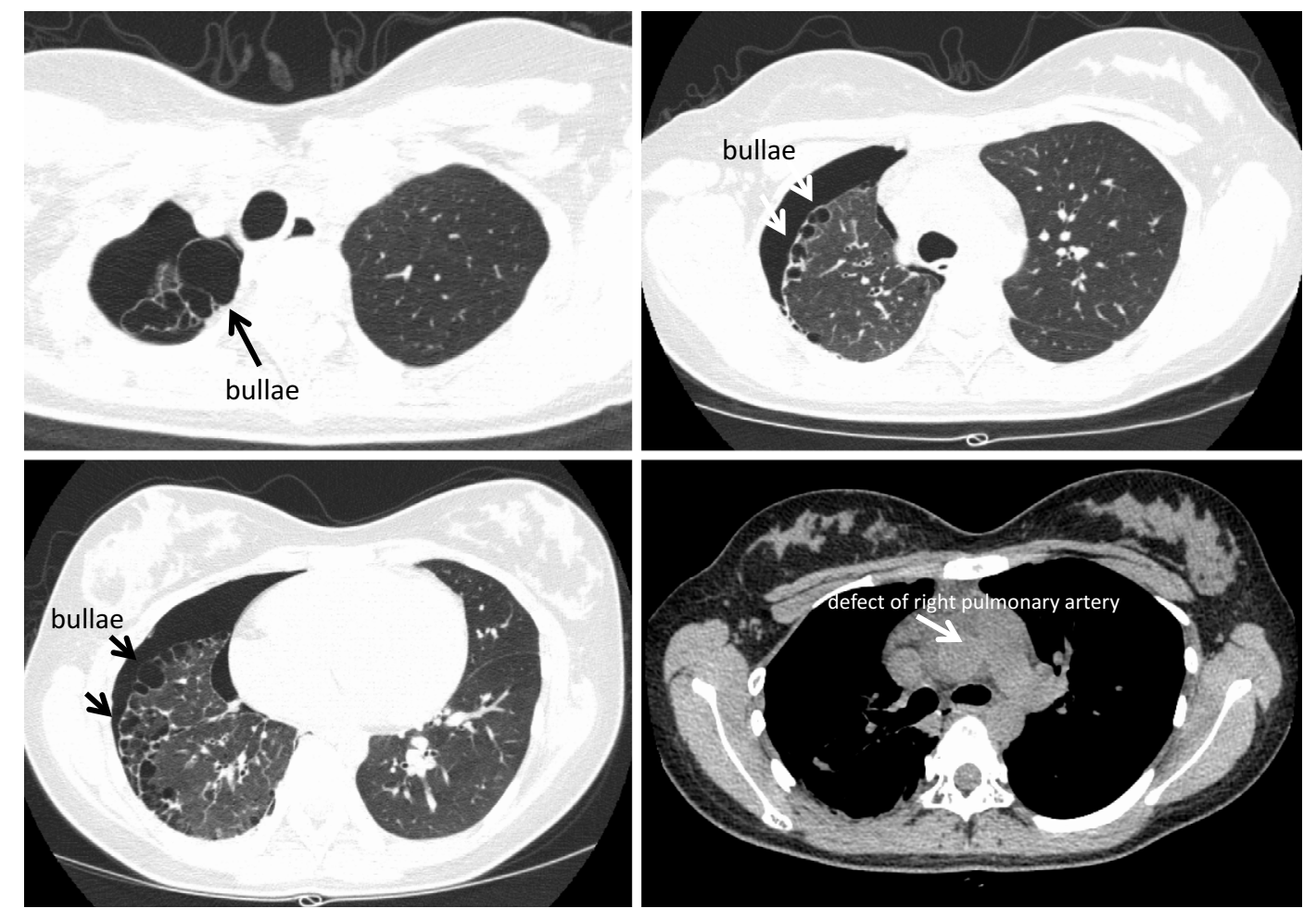

Picture 2.

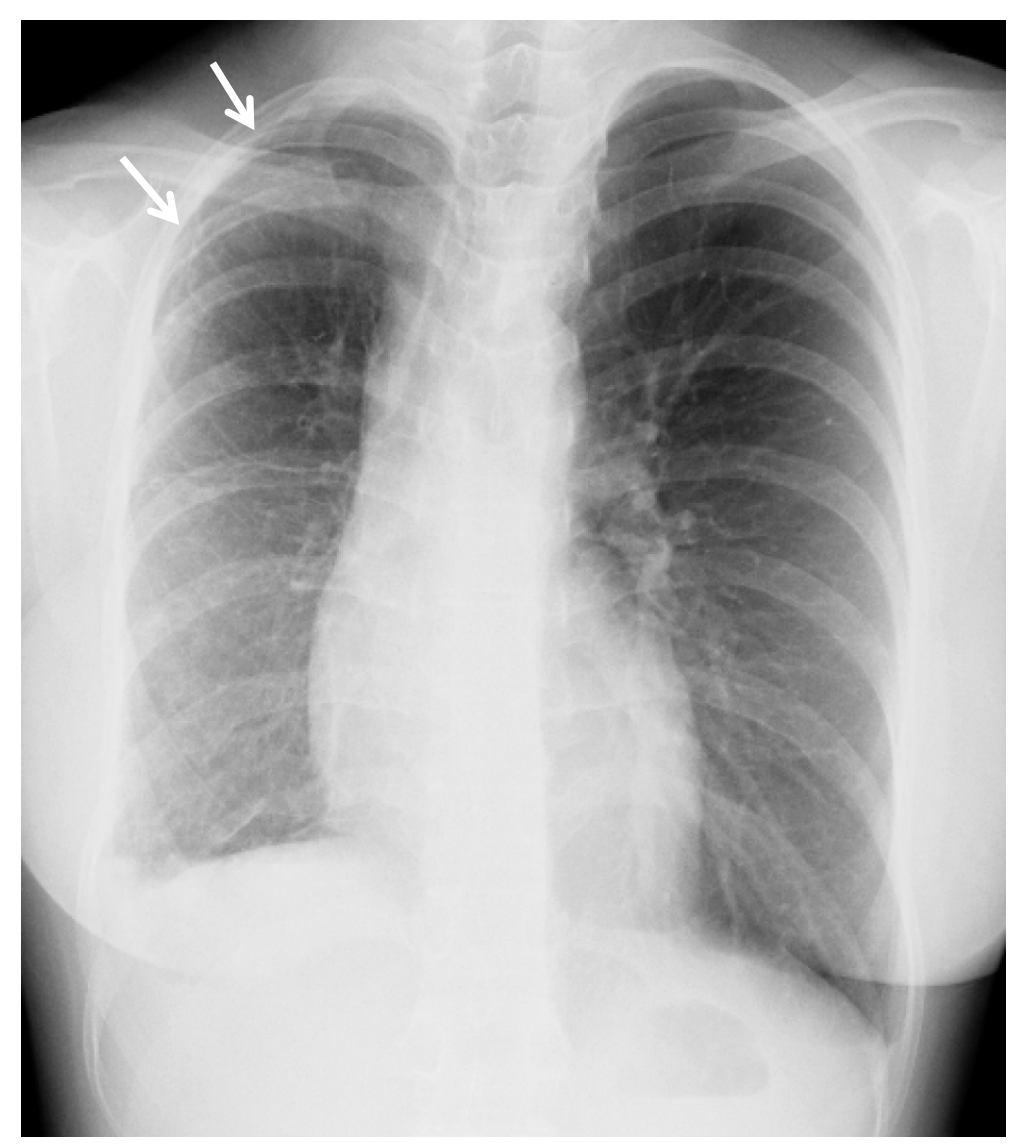

Picture 3. 


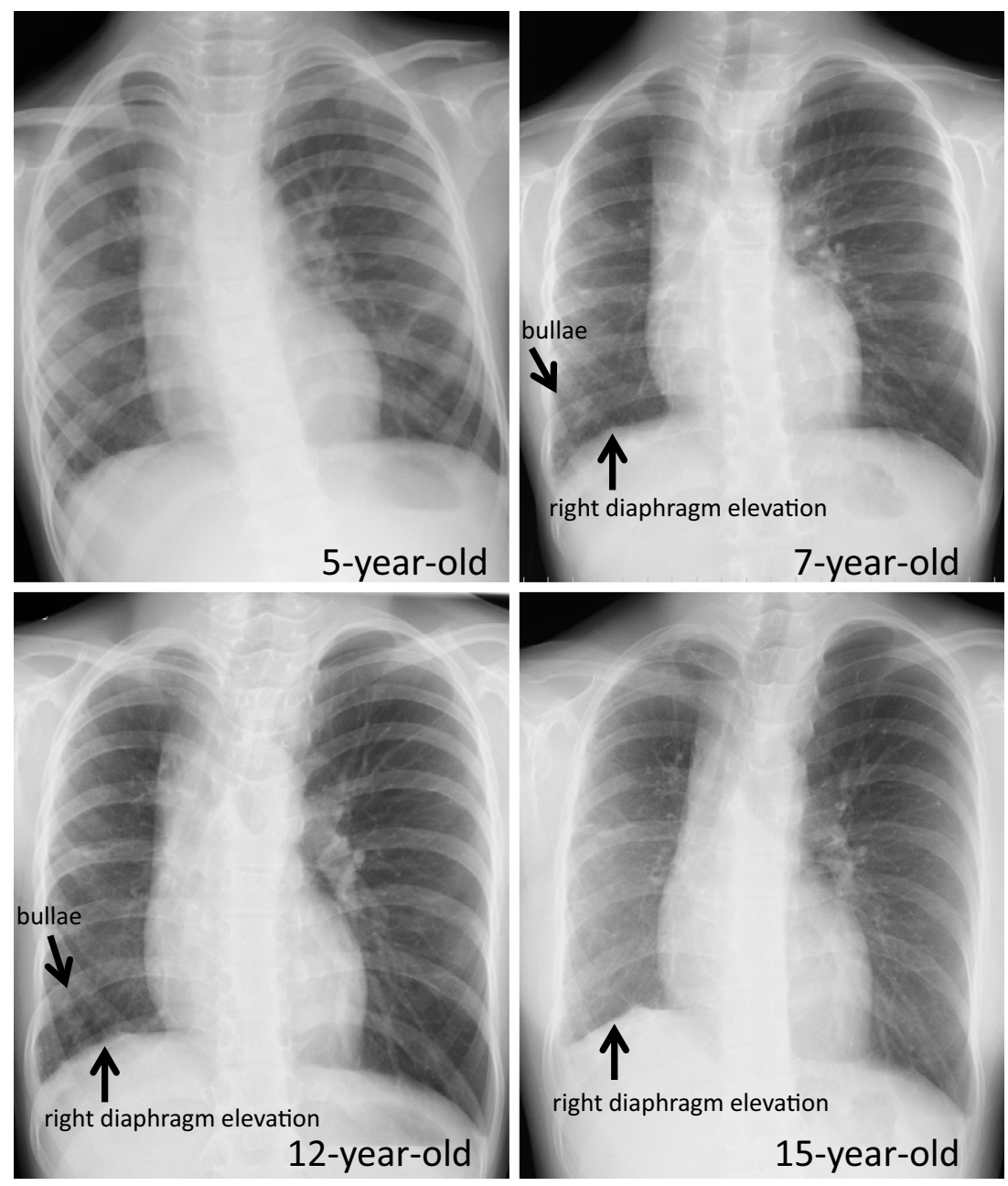

Picture 4.

the previous chest radiography findings, the right-sided reduction in lung volume, elevated right diaphragm and bullous lung disease showed slow progression (Picture 4). Isolated UAPA is a rare congenital anomaly, and only a few cases of bullous lung disease in UAPA patients have been reported $(1,2)$. This is the first report of a patient with UAPA and pneumothorax on the side of the affected lung.

The authors state that they have no Conflict of Interest (COI).

\section{References}

1. Vithakumar MB, Anupama VB, Bathal VS, et al. Bullous lung disease and bronchiectasis in unilateral absent right pulmonary artery. Gen Thorac Cardiovasc Surg 61: 100-103, 2013.

2. Kucera V, Fiser B, Tuma S, et al. Unilateral absence of pulmonary artery: a report on 19 selected clinical cases. J Thorac Cardiovasc Surg 30: 152-158, 1982.

The Internal Medicine is an Open Access article distributed under the Creative Commons Attribution-NonCommercial-NoDerivatives 4.0 International License. To view the details of this license, please visit (https://creativecommons.org/licenses/ by-nc-nd/4.0/).

(C) 2018 The Japanese Society of Internal Medicine Intern Med 57: 145-147, 2018 